\title{
Long-term impact of obesity on patient-reported outcomes and patient satisfaction after lumbar spine surgery: an observational study
}

\author{
Christine Park, BA, ${ }^{1}$ Alessandra N. Garcia, PT, PhD, ${ }^{2}$ Chad Cook, PT, PhD, ${ }^{2}$ \\ Christopher I. Shaffrey, MD, ${ }^{1}$ and Oren N. Gottfried, MD ${ }^{1}$ \\ 'Department of Neurosurgery, Duke University Medical Center; and 2Division of Physical Therapy, Department of Orthopaedic
Surgery, Duke University, Durham, North Carolina
}

\begin{abstract}
OBJECTIVE Obese body habitus is a challenging issue to address in lumbar spine surgery. There is a lack of consensus on the long-term influence of BMI on patient-reported outcomes and satisfaction. This study aimed to examine the differences in patient-reported outcomes over the course of 12 and 24 months among BMI classifications of patients who underwent lumbar surgery.
\end{abstract}

METHODS A search was performed using the Quality Outcomes Database (QOD) Spine Registry from 2012 to 2018 to identify patients who underwent lumbar surgery and had either a 12- or 24-month follow-up. Patients were categorized based on their BMl as normal weight $\left(\leq 25 \mathrm{~kg} / \mathrm{m}^{2}\right)$, overweight $\left(25-30 \mathrm{~kg} / \mathrm{m}^{2}\right)$, obese $\left(30-40 \mathrm{~kg} / \mathrm{m}^{2}\right)$, and morbidly obese $\left(>40 \mathrm{~kg} / \mathrm{m}^{2}\right.$ ). Outcomes included the Oswestry Disability Index (ODI) and the visual analog scale (VAS) for back pain (BP) and leg pain (LP), and patient satisfaction was measured at 12 and 24 months postoperatively.

RESULTS A total of 31,765 patients were included. At both the 12- and 24-month follow-ups, those who were obese and morbidly obese had worse ODI, VAS-BP, and VAS-LP scores (all $p<0.01$ ) and more frequently rated their satisfaction as "I am the same or worse than before treatment" (all $p<0.01$ ) compared with those who were normal weight. Receiver operating characteristic curve analysis revealed that the BMI cutoffs for predicting worsening disability and surgery dissatisfaction were $30.1 \mathrm{~kg} / \mathrm{m}^{2}$ and $29.9 \mathrm{~kg} / \mathrm{m}^{2}$ for the 12 - and 24 -month follow-ups, respectively.

CONCLUSIONS Higher BMI was associated with poorer patient-reported outcomes and satisfaction at both the 12-and 24-month follow-ups. BMl of $30 \mathrm{~kg} / \mathrm{m}^{2}$ is the cutoff for predicting worse patient outcomes after lumbar surgery.

https://thejns.org/doi/abs/10.3171/2020.6.SPINE20592

KEYWORDS obesity; patient-reported outcomes; patient satisfaction; lumbar spine surgery

$\mathrm{O}$ BESE body habitus is a prevalent and costly condition that has been a growing health concern over the past several decades worldwide, affecting approximately $35 \%$ of people in the United States., ${ }^{1,2}$ Among its many associated medical complications, including hypertension, diabetes mellitus, and coronary artery disease, obesity has historically been correlated with a higher incidence of musculoskeletal disorders with increasing age.,4, Hence, with the advancement of medicine and the resulting growth of the aging population, spine surgeons are likely to encounter more cases of obese patients who require surgical intervention and are at higher risk for postoperative complications. ${ }^{5,6}$

BMI is one of the clinical measures commonly used to measure body habitus. ${ }^{7}$ Previous studies have shown high BMI to be an independent risk factor for higher hospital costs for spine surgery due to increased blood loss, prolonged operative time, early reoperation rates, and higher complication rates.$^{8-11}$ Despite these postoperative difficulties, further research revealed that both nonobese

ABBREVIATIONS $A U C=$ area under the ROC curve; $M C I D=$ minimal clinically important difference; $M D=$ mean difference; NASS = North American Spine Society; ODI = Oswestry Disability Index; $\mathrm{QOD}=$ Quality Outcomes Database; ROC = receiver operating characteristic; VAS-BP = visual analog scale for back pain; VAS-LP = VAS for leg pain.

SUBMITTED April 14, 2020. ACCEPTED June 1, 2020.

INCLUDE WHEN CITING Published online September 25, 2020; DOI: 10.3171/2020.6.SPINE20592. 
and obese spine surgery patients, although to different degrees, experienced pain relief and functional improvement overall after undergoing the same procedures. ${ }^{10,12-14}$

Although there are reports in the literature indicating that patient-reported outcomes are comparable between nonobese and obese patients who underwent lumbar spine surgery, there is a lack of data on long-term clinical outcomes and patient satisfaction following lumbar surgery in a large patient sample size. ${ }^{15}$ Existing large, retrospective studies mostly focus on postoperative complications. ${ }^{11,16}$ Furthermore, the BMI categorization has been arbitrary between different studies. In this study, we aimed to evaluate differences in selected outcomes across different BMI categorizations. We considered BMI on a continuous spectrum and classified it using recommended thresholds to see if historical classifications led to differences in long-term clinical outcomes and patient satisfaction after lumbar surgery. We also investigated whether there was a BMI threshold that predicted negative outcomes using BMI as a continuous measure. We hypothesized that patients with higher BMI would experience less improvement in patient-reported outcomes and would have lower satisfaction in the long term compared with those with lower BMI.

\section{Methods \\ Study Design and Setting}

This was a retrospective, observational study using the Quality Outcomes Database (QOD) Spine Registry from 2012 to 2018 approved by the IRB. Patient consent was not sought because patients were not subjected to any intervention resulting from this study. The QOD is a prospective observational registry that reports the risk-adjusted expected morbidity and 1- to 2-year patient outcomes for lumbar cases performed by spine surgeons. ${ }^{17,18}$ It is a powerful collection of quality data that can be used to determine the efficacy of surgical treatments and to facilitate clinical decision-making and resource allocation. The study is reported using the Strengthening the Reporting of Observational Studies in Epidemiology (STROBE) statement. ${ }^{19}$

\section{Participants}

Our population consisted of adult patients who underwent lumbar spine surgery with either a 12- or 24-month follow-up between 2012 and 2018. The types of lumbar surgeries included microdiscectomy or laminectomy with or without fusion. Patients who did not have complete records (i.e., all patient-reported outcomes of interest) up to the target follow-up time point and had revision surgeries were excluded from the study. Patients were categorized based on their BMI as normal weight (BMI $\left.\leq 25 \mathrm{~kg} / \mathrm{m}^{2}\right)$, overweight $\left(25-30 \mathrm{~kg} / \mathrm{m}^{2}\right)$, obese $\left(30-40 \mathrm{~kg} / \mathrm{m}^{2}\right)$, and morbidly obese $\left(>40 \mathrm{~kg} / \mathrm{m}^{2}\right) .{ }^{20}$ After applying these inclusion and exclusion criteria, a total of 31,765 patients were included: 27,164 were included in the 12-month cohort and 4601 in the 24-month cohort (Fig. 1).

\section{Variables}

Descriptive variables for each 12- and 24-month cohort included the following demographic and clinical variables: age, sex, ethnicity, level of education, insurance type, predominant symptoms and their duration and location, prior surgery, smoking status, and comorbidities (e.g., diabetes, coronary artery disease, peripheral vascular disease, anxiety, depression, osteoarthritis, osteoporosis, renal disease, and chronic obstructive pulmonary disease).

Outcomes included back and leg pain intensity, disability, and patient satisfaction collected at 12 and 24 months postoperatively. Back pain and leg pain were measured quantitatively using the visual analog scale (VAS; VAS$\mathrm{BP}$ and VAS-LP, respectively), a reliable scale that ranges from 0 to 10 (in which 0 represents "no pain" and 10 represents the "worst possible pain"). ${ }^{21}$ The Oswestry Disability Index (ODI) was used to measure disability. It is a wellestablished tool in the clinical setting that reliably assesses the performance status of patients with spinal disorders. ${ }^{22}$ Scores range from $0 \%$ to $100 \%$ and are calculated by dividing the total possible score by the total obtained score: 0\%-20\% indicates minimal disability; $21 \%-40 \%$, moderate disability; $41 \%-60 \%$, severe disability; $61 \%-80 \%$, crippled; and $80 \%-100 \%$, bedbound or symptom exaggeration.

Patient satisfaction was captured using the North American Spine Society (NASS) patient satisfaction index that has demonstrated high reliability and validity. ${ }^{23}$ Patients can rate their contentment with scores between 1 and 4 . A score of 1 indicates "the treatment met my expectations," 2 indicates "I did not improve as much as I had hoped, but I would undergo the same treatment for the same outcome;" 3 indicates "I did not improve as much as I had hoped, and I would not undergo the same treatment for the same outcome," and 4 indicates "I am the same or worse than before treatment."

\section{Statistical Analysis}

Descriptive categorical and continuous variables were summarized using frequency counts (percentages) and means (standard deviations), respectively. A generalized linear model was performed for continuous variables (including 95\% CIs). Pearson's chi-square test was carried out for categorical variables. Multivariate analysis was run by considering prior surgery to the spine, hip, or knee; comorbidities; and ODI, VAS-BP, and VAS-LP scores at baseline as covariates to determine the adjusted mean difference (MD) of ODI, VAS-BP, and VAS-LP scores at 12 and 24 months postoperatively. The normal-weight group was used as the reference group for calculating the MD and statistical significance. In addition, the receiver operating characteristic (ROC) curve method was used to determine whether BMI was able to accurately predict 12- and 24-month worsening disability (ODI > 48) and patient satisfaction. ${ }^{24}$ In our analysis, ROC curves were generated using BMI as a test variable and disability and satisfaction as state variables. We interpreted the performance of analysis using the area under the ROC curve (AUC) in which higher AUC values $(\geq 0.70)$ indicate better performance. ${ }^{25}$ Statistical significance was set at $p<0.05$ for all tests. Because Little's test of missing completely at random suggested the data were not missing at random, we elected to use listwise deletion, a statistical method for 


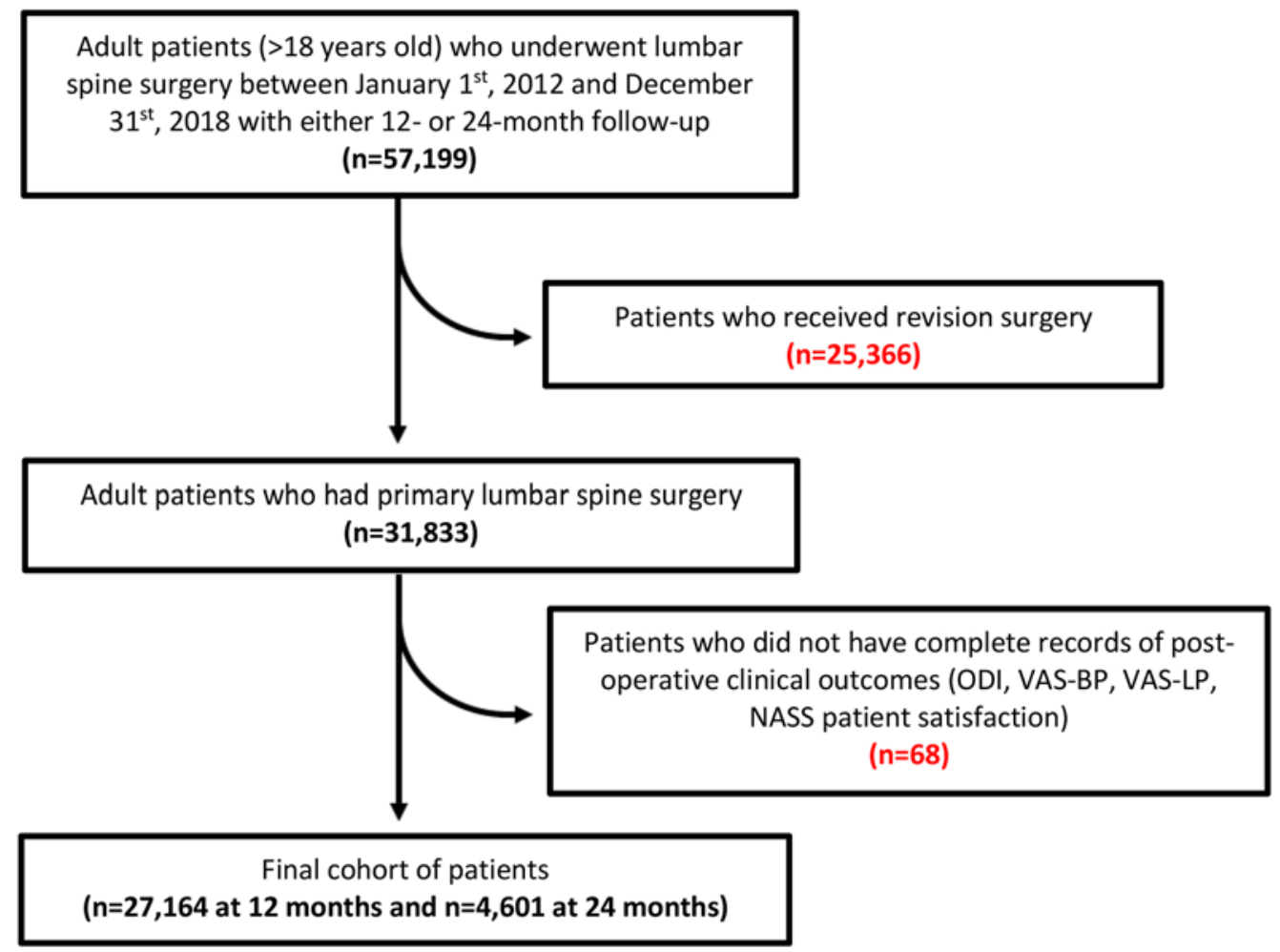

FIG. 1. CONSORT diagram used for selection of the patient population. Figure is available in color online only.

handling missing data. ${ }^{26}$ In this method, an entire record is excluded from analysis if any single value is missing. All analyses were conducted in IBM SPSS software (version 25.0, IBM Corp.).

\section{Results}

\section{Baseline Characteristics of Lumbar Spinal Surgery Patients at the 12- and 24-Month Follow-Ups}

The baseline characteristics (including any presenting symptoms) and demographics of patients who were either in the 12-month or 24-month follow-up cohorts are summarized in Tables 1 and 2, respectively. Overall, patients in both cohorts were similar in baseline demographics and characteristics.

\section{Patient-Reported Outcomes at the 12-Month Follow-Up}

The patient-reported outcomes at the 12-month followup are reported in Table 3. At the 12-month follow-up after accounting for covariates, we found that normal weight to overweight patients had similarly improved ODI scores (normal weight: $28.57 \%$ [95\% CI $25.51 \%-31.63 \%$ ]; overweight: $28.56 \%$ [95\% CI $25.52 \%-31.60 \%]$ ), while those who were obese and morbidly obese had worse outcomes than those who were normal weight (obese: $\mathrm{MD}=2.30 \%$ [95\% CI $1.58 \%-3.03 \%, \mathrm{p}<0.01]$ and morbidly obese: MD $=5.91 \%[95 \% \mathrm{CI}=4.71 \%-7.11 \%, \mathrm{p}<0.01])$. Similarly, we found that patients with lower BMIs had better improvement in VAS-BP scores (normal weight: 3.58 [95\% CI 3.26-3.89] and overweight: 3.56 [95\% CI 3.25-3.87] vs obese: 3.76 [95\% CI 3.45-4.07] with MD $=0.18[95 \%$ CI $0.07-0.29, \mathrm{p}<0.01]$ and morbidly obese: $4.24[95 \%$ CI 3.91-4.58] with $\mathrm{MD}=0.67$ [95\% CI 0.49-0.84, $\mathrm{p}<$ $0.01]$ ) and VAS-LP scores (normal weight: 3.28 [95\% CI 2.72-3.84] and overweight: 3.22 [95\% CI 2.66-3.77] vs obese: 3.49 [95\% CI 2.93-4.05] with $\mathrm{MD}=0.21$ [95\% CI $0.09-0.33, \mathrm{p}<0.01]$ and morbidly obese: 3.84 [95\% CI 3.27-4.41] with MD 0.56 [95\% CI 0.37-0.75, p < 0.01]).

A higher proportion of patients in the higher BMI group rated their satisfaction as a 4 compared with those in the lower BMI group $(8.15 \%$ and $7.99 \%$ for normal weight and overweight vs $8.86 \%$ and $11.89 \%$ for obese and morbidly obese, respectively; $\mathrm{p}<0.01$ ). Also, patients with a higher BMI expressed improvement with a mixed rating for the efficacy of surgery, with a greater number of patients who gave their outcomes a score of $3(6.10 \%$ and $5.68 \%$ for normal weight and overweight vs $6.75 \%$ and $7.57 \%$ for obese and morbidly obese, respectively; $\mathrm{p}<0.01$ ) or a score of 2 (19.83\% and $19.58 \%$ for normal weight and overweight vs $21.62 \%$ and $23.82 \%$ for obese and morbidly obese, respectively; $\mathrm{p}<0.01)$.

\section{Patient-Reported Outcomes at the 24-Month Follow-Up}

The patient-reported outcomes at the 24-month followup are reported in Table 4. After accounting for the covariates as described previously for the 12-month group, we found that the ODI scores (normal weight: $27.47 \%$ [95\% CI 23.87\%-31.08\%] and overweight: $27.89 \%$ [95\% CI $24.36 \%-31.41 \%$ ] vs obese: $30.46 \%$ [95\% CI $27.03 \%-$ $33.89 \%$ ] with $\mathrm{MD}=2.98 \%$ [95\% CI $1.24 \%-4.72 \%, \mathrm{p}<0.01]$ 
TABLE 1. Characteristics of surgical recipients by BMI classification at the 12-month follow-up $(n=27,164)$

\begin{tabular}{|c|c|c|c|c|c|}
\hline Variable & $\begin{array}{l}\text { Normal Weight } \\
\qquad(n=5,029)\end{array}$ & $\begin{array}{l}\text { Overweight } \\
(n=9,222)\end{array}$ & $\begin{array}{c}\text { Obese } \\
(n=10,852)\end{array}$ & $\begin{array}{l}\text { Morbidly Obese } \\
\quad(n=2,061)\end{array}$ & $\begin{array}{c}p \\
\text { Value }\end{array}$ \\
\hline Mean age, yrs $(95 \% \mathrm{Cl})$ & $59.72(59.29-60.14)$ & $60.94(60.66-61.23)$ & $59.46(59.21-59.72)$ & $54.61(54.02-55.19)$ & $<0.01$ \\
\hline Sex & & & & & $<0.01$ \\
\hline Male & $2,061(40.98)$ & $5,427(58.85)$ & $5,936(54.70)$ & $822(39.88)$ & \\
\hline Female & $2,966(58.98)$ & $3,794(41.14)$ & $4,913(45.27)$ & $1,239(60.12)$ & \\
\hline Ethnicity (Hispanic or Latino) & $104(2.07)$ & $199(2.16)$ & $289(2.67)$ & $48(2.33)$ & 0.03 \\
\hline Level of education & & & & & $<0.01$ \\
\hline Less than high school & $211(4.20)$ & $418(4.53)$ & $560(5.16)$ & $103(5.00)$ & \\
\hline High school diploma & $1,780(35.39)$ & $3,663(39.72)$ & $4,792(44.16)$ & $1,010(49.01)$ & \\
\hline 2-yr college degree & $844(16.78)$ & $1,497(16.23)$ & 2,077 (19.14) & $405(19.65)$ & \\
\hline 4-yr college degree & $1,107(22.01)$ & $1,843(20.00)$ & $1,884(17.36)$ & $294(14.26)$ & \\
\hline Postcollege & $963(19.15)$ & $1,519(16.47)$ & $1,274(11.74)$ & $202(9.80)$ & \\
\hline Insurance type & & & & & $<0.01$ \\
\hline Uninsured & $42(0.84)$ & $73(0.79)$ & $96(0.88)$ & $24(1.16)$ & \\
\hline Medicare & $1,959(38.95)$ & $3,917(42.47)$ & $4,206(38.76)$ & $622(30.18)$ & \\
\hline Medicaid & $203(4.04)$ & $291(3.16)$ & $503(4.64)$ & $177(8.59)$ & \\
\hline Veterans Affairs/government & $113(2.25)$ & $287(3.11)$ & $365(3.36)$ & $66(3.20)$ & \\
\hline Private & $2,704(53.77)$ & $4,646(50.38)$ & $5,666(52.21)$ & $1,170(56.77)$ & \\
\hline Mean BMI $(95 \% \mathrm{Cl})$ & $22.69(22.64-22.74)$ & $27.53(27.51-27.56)$ & $33.91(33.85-33.96)$ & $44.27(44.09-44.45)$ & $<0.01$ \\
\hline Mean duration of symptoms, mos $(95 \% \mathrm{Cl})$ & $1.89(1.88-1.90)$ & $1.90(1.90-1.91)$ & $1.92(0.00-1.91)$ & $1.93(1.92-1.95)$ & $<0.01$ \\
\hline Received prior surgery* & $1,050(20.88)$ & $2,207(23.93)$ & $2,870(26.45)$ & $583(28.29)$ & $<0.01$ \\
\hline Current smoker & & & & & $<0.01$ \\
\hline Every day or almost daily & $893(17.76)$ & $1,186(12.86)$ & $1,338(12.33)$ & $259(12.57)$ & \\
\hline Some days or occasional & $101(2.01)$ & $174(1.89)$ & $190(1.75)$ & $38(1.84)$ & \\
\hline Predominant symptom & & & & & 0.16 \\
\hline Pain & $4,067(80.87)$ & $7,557(81.95)$ & $8,873(81.76)$ & $1,694(82.19)$ & \\
\hline Weakness & $175(3.48)$ & $369(4.00)$ & $436(4.02)$ & $86(4.17)$ & \\
\hline Numbness & $550(10.94)$ & $915(9.92)$ & $1,094(10.08)$ & $189(9.17)$ & \\
\hline Predominant location of symptom & & & & & $<0.01$ \\
\hline Back & $1,041(20.70)$ & $1,944(21.08)$ & $2,531(23.32)$ & $500(24.26)$ & \\
\hline Leg & $1,886(37.50)$ & $3,276(35.52)$ & $3,375(31.10)$ & $558(27.07)$ & \\
\hline Both back \& leg & $2,100(41.76)$ & $3,996(43.33)$ & $4,941(45.53)$ & $1,001(48.57)$ & \\
\hline Mean baseline ODI score $(95 \% \mathrm{Cl})$ & $45.55(45.07-46.04)$ & $44.32(43.97-44.67)$ & $46.78(46.47-47.10)$ & $46.78(46.47-47.10)$ & $<0.01$ \\
\hline Mean baseline VAS-BP score $(95 \% \mathrm{CI})$ & $6.26(6.18-6.34)$ & $6.31(6.25-6.36)$ & $6.69(6.64-6.74)$ & $7.12(7.01-7.23)$ & $<0.01$ \\
\hline Mean baseline VAS-LP score $(95 \% \mathrm{CI})$ & $6.76(6.69-6.84)$ & $6.66(6.60-6.72)$ & $6.78(6.73-6.83)$ & $7.13(7.01-7.24)$ & $<0.01$ \\
\hline \multicolumn{6}{|l|}{ Comorbidities prior to surgery } \\
\hline Diabetes & $417(8.30)$ & $1,329(14.41)$ & $2,669(24.59)$ & $643(31.20)$ & $<0.01$ \\
\hline Coronary artery disease & $442(8.79)$ & $1,030(11.17)$ & $1,375(12.67)$ & $232(11.26)$ & $<0.01$ \\
\hline Peripheral vascular disease & $77(1.53)$ & $167(1.81)$ & $230(2.12)$ & $46(2.23)$ & $<0.01$ \\
\hline Anxiety & $851(16.92)$ & $1,404(15.22)$ & $1,851(17.06)$ & $455(22.08)$ & $<0.01$ \\
\hline Depression & $910(18.10)$ & $1,611(17.47)$ & $2,422(22.32)$ & $576(27.95)$ & $<0.01$ \\
\hline Osteoarthritis $\dagger$ & $753(14.97)$ & $1,473(15.97)$ & $2,099(19.34)$ & $459(22.27)$ & $<0.01$ \\
\hline Osteoporosis & $400(7.95)$ & $380(4.12)$ & $369(3.40)$ & $76(3.69)$ & $<0.01$ \\
\hline Renal disease & $90(1.79)$ & $185(2.01)$ & $264(2.43)$ & $74(3.59)$ & $<0.01$ \\
\hline Chronic obstructive pulmonary disease & $191(3.80)$ & $322(3.50)$ & $450(4.15)$ & $109(5.29)$ & $<0.01$ \\
\hline
\end{tabular}

Values represent the number of patients (\%) unless otherwise indicated. Percentages are based on the total number of patients per group regardless if data are missing from the category. Boldface type indicates statistical significance.

${ }^{*}$ Prior surgery for spine, hip, or knee.

$\dagger$ Hip, shoulder, or knee. 
TABLE 2. Characteristics of surgical recipients by BMI classification at the 24-month follow-up ( $n=4,601)$

\begin{tabular}{|c|c|c|c|c|c|}
\hline Variable & $\begin{array}{l}\text { Normal Weight } \\
\quad(n=866)\end{array}$ & $\begin{array}{l}\text { Overweight } \\
(n=1,591)\end{array}$ & $\begin{array}{c}\text { Obese } \\
(n=1,810)\end{array}$ & $\begin{array}{l}\text { Morbidly Obese } \\
\qquad(n=334)\end{array}$ & $\begin{array}{c}p \\
\text { Value }\end{array}$ \\
\hline Mean age, yrs $(95 \% \mathrm{Cl})$ & $58.67(57.63-59.72)$ & $60.16(59.47-60.85)$ & $58.42(57.80-59.03)$ & 53.39 (51.97-54.81) & $<0.01$ \\
\hline Sex & & & & & $<0.01$ \\
\hline Male & $365(42.14)$ & $926(58.20)$ & $1,005(55.52)$ & $129(38.62)$ & \\
\hline Female & $501(57.85)$ & $664(41.73)$ & $804(44.42)$ & $205(61.38)$ & \\
\hline Ethnicity (Hispanic or Latino) & $11(1.27)$ & $32(2.01)$ & $36(1.99)$ & $4(1.20)$ & 0.43 \\
\hline Level of education & & & & & $<0.01$ \\
\hline Less than high school & $39(4.50)$ & $72(4.53)$ & $84(4.64)$ & $13(3.89)$ & \\
\hline High school diploma & $257(29.68)$ & $603(37.90)$ & $732(40.44)$ & $154(46.11)$ & \\
\hline 2-yr college degree & $128(14.78)$ & $236(14.83)$ & $331(18.29)$ & $60(17.96)$ & \\
\hline 4-yr college degree & $215(24.83)$ & $325(20.43)$ & $358(19.78)$ & $66(19.76)$ & \\
\hline Postcollege & $200(23.09)$ & $282(17.72)$ & $242(13.37)$ & $30(8.98)$ & \\
\hline Insurance type & & & & & $<0.01$ \\
\hline Uninsured & $1(0.12)$ & $6(0.38)$ & $10(0.55)$ & $1(0.30)$ & \\
\hline Medicare & $293(33.83)$ & $632(39.72)$ & $667(36.85)$ & $91(27.25)$ & \\
\hline Medicaid & $42(4.85)$ & $58(3.65)$ & $86(4.75)$ & $31(9.28)$ & \\
\hline Veterans Affairs/government & $21(2.42)$ & $40(2.51)$ & $51(2.82)$ & $10(2.99)$ & \\
\hline Private & $508(58.66)$ & $853(53.61)$ & $995(54.97)$ & $201(60.17)$ & \\
\hline Mean BMI $(95 \% \mathrm{Cl})$ & $22.67(22.55-22.79)$ & $27.54(27.47-27.61)$ & $33.81(33.69-33.93)$ & $44.25(43.83-44.67)$ & $<0.01$ \\
\hline Mean duration of symptoms, mos $(95 \% \mathrm{Cl})$ & $1.94(1.91-1.96)$ & $1.94(1.92-1.95)$ & $1.92(1.90-1.94)$ & $1.94(1.90-1.98)$ & $<0.01$ \\
\hline Received prior surgery* & $132(15.24)$ & $293(18.42)$ & $345(19.06)$ & $72(21.56)$ & 0.03 \\
\hline Current smoker & & & & & $<0.01$ \\
\hline Every day or almost daily & $162(18.71)$ & $190(11.94)$ & $242(13.37)$ & $40(11.98)$ & \\
\hline Some days or occasional & $12(1.39)$ & $25(1.57)$ & $29(1.60)$ & $5(1.50)$ & \\
\hline Predominant symptom & & & & & 0.49 \\
\hline Pain & $736(84.99)$ & $1,373(86.30)$ & $1,548(85.52)$ & $288(86.23)$ & \\
\hline Weakness & $25(2.89)$ & $40(2.51)$ & $67(3.70)$ & $10(2.99)$ & \\
\hline Numbness & $89(10.28)$ & $150(9.43)$ & $172(9.50)$ & $27(8.08)$ & \\
\hline Predominant location of symptom & & & & & $<0.01$ \\
\hline Back & $194(22.40)$ & $364(22.88)$ & $446(24.64)$ & $86(25.75)$ & \\
\hline Leg & $332(38.34)$ & $562(35.32)$ & $524(28.95)$ & $67(20.06)$ & \\
\hline Both back \& leg & $340(39.26)$ & $665(41.80)$ & $840(46.41)$ & $181(54.19)$ & \\
\hline Mean baseline ODI score $(95 \% \mathrm{CI})$ & $46.05(44.87-47.24)$ & $44.20(43.33-45.07)$ & $47.49(46.68-48.30)$ & $53.37(51.69-55.05)$ & $<0.01$ \\
\hline Mean baseline VAS-BP score $(95 \% \mathrm{CI})$ & $6.29(6.10-6.48)$ & $6.21(6.06-6.35)$ & $6.60(6.48-6.73)$ & $7.30(7.04-7.56)$ & $<0.01$ \\
\hline Mean baseline VAS-LP score $(95 \% \mathrm{CI})$ & $6.69(6.50-6.87)$ & $6.62(6.48-6.76)$ & $6.82(6.69-6.94)$ & $7.40(7.13-7.67)$ & $<0.01$ \\
\hline \multicolumn{6}{|l|}{ Comorbidities prior to surgery } \\
\hline Diabetes & $73(8.43)$ & $218(13.70)$ & $416(22.98)$ & $104(31.14)$ & $<0.01$ \\
\hline Coronary artery disease & $101(11.66)$ & $217(13.64)$ & $250(13.81)$ & $40(11.98)$ & 0.15 \\
\hline Peripheral vascular disease & $33(3.81)$ & $57(3.58)$ & $57(3.15)$ & $15(4.49)$ & 0.75 \\
\hline Anxiety & $148(17.09)$ & $225(14.14)$ & $360(19.89)$ & $83(24.85)$ & $<0.01$ \\
\hline Depression & $165(19.05)$ & $273(17.16)$ & $425(23.48)$ & $90(26.95)$ & $<0.01$ \\
\hline Osteoarthritis $†$ & $175(20.21)$ & $347(21.81)$ & $448(24.75)$ & $93(27.84)$ & 0.01 \\
\hline Osteoporosis & $57(6.58)$ & $51(3.21)$ & $51(2.82)$ & $10(2.99)$ & $<0.01$ \\
\hline Renal disease & $21(2.42)$ & $28(1.76)$ & $47(2.60)$ & $10(2.99)$ & $<0.01$ \\
\hline Chronic obstructive pulmonary disease & $34(3.93)$ & $55(3.46)$ & $62(3.43)$ & $18(5.39)$ & 0.17 \\
\hline
\end{tabular}

Values represent the number of patients (\%) unless otherwise indicated. Percentages are based on the total number of patients per group regardless if data are missing from the category. Boldface type indicates statistical significance.

* Prior surgery for spine, hip, or knee.

† Hip, shoulder, or knee. 
TABLE 3. Outcome differences between groups at 12 months

\begin{tabular}{|c|c|c|c|c|c|c|c|}
\hline $\begin{array}{l}\text { Outcome } \\
\text { Measure }\end{array}$ & $\begin{array}{l}\text { Normal Weight } \\
\qquad(n=5,029)\end{array}$ & $\begin{array}{l}\text { Overweight } \\
(n=9,222)\end{array}$ & $\begin{array}{c}p \\
\text { Value }\end{array}$ & $\begin{array}{c}\text { Obese } \\
(n=10,852)\end{array}$ & $\begin{array}{c}p \\
\text { Value }\end{array}$ & $\begin{array}{l}\text { Morbidly Obese } \\
\quad(n=2,061)\end{array}$ & $\begin{array}{c}p \\
\text { Value }\end{array}$ \\
\hline \multicolumn{8}{|l|}{ ODI score (95\% Cl) } \\
\hline Unadjusted mean & 20.08 (19.55 to 20.61$)$ & 19.68 (19.30 to 20.07$)$ & & 23.46 (23.08 to 23.84$)$ & & 28.94 (27.99 to 29.90$)$ & \\
\hline Adjusted mean & 28.57 (25.51 to 31.63 ) & 28.56 (25.52 to 31.60$)$ & & 30.88 (27.84 to 33.92$)$ & & 34.49 (31.33 to 37.66$)$ & \\
\hline Adjusted MD & & $0.00(-0.71$ to 0.73$)$ & 0.97 & 2.30 (1.58 to 3.03$)$ & $<0.01$ & 5.91 (4.71 to 7.11$)$ & $<0.01$ \\
\hline \multicolumn{8}{|c|}{ VAS-BP score $(95 \% \mathrm{CI})$} \\
\hline Unadjusted mean & 2.78 (2.70 to 2.86$)$ & 2.82 (2.76 to 2.87 ) & & 3.20 (3.15 to 3.26$)$ & & 3.78 (3.65 to 3.92 ) & \\
\hline Adjusted mean & 3.58 (3.26 to 3.89$)$ & 3.56 (3.25 to 3.87$)$ & & 3.76 (3.45 to 4.07$)$ & & 4.24 (3.91 to 4.58$)$ & \\
\hline Adjusted MD & & $0.02(-0.09$ to 0.13$)$ & 0.74 & $0.18(0.07$ to 0.29$)$ & $<0.01$ & 0.67 (0.49 to 0.84$)$ & $<0.01$ \\
\hline \multicolumn{8}{|c|}{ VAS-LP score $(95 \% \mathrm{CI})$} \\
\hline Unadjusted mean & 2.29 (2.21 to 2.37$)$ & 2.24 (2.18 to 2.30$)$ & & 2.58 (2.53 to 2.64$)$ & & 3.00 (2.86 to 3.14$)$ & \\
\hline Adjusted mean & 3.28 (2.72 to 3.84 ) & 3.22 (2.66 to 3.77 ) & & 3.49 (2.93 to 4.05$)$ & & 3.84 (3.27 to 4.41$)$ & \\
\hline Adjusted MD & & $0.06(-0.05$ to 0.18$)$ & 0.27 & 0.21 (0.09 to 0.33$)$ & $<0.01$ & $0.56(0.37$ to 0.75$)$ & $<0.01$ \\
\hline \multicolumn{8}{|l|}{$\begin{array}{l}\text { Unadjusted mean } \\
\text { NASS score, } n(\%)^{*}\end{array}$} \\
\hline 1 & $3,294(65.50)$ & $6,117(66.33)$ & \multirow{4}{*}{$<0.01$} & $6,760(62.29)$ & \multirow{4}{*}{$<0.01$} & $1,160(56.28)$ & \multirow{4}{*}{$<0.01$} \\
\hline 2 & $997(19.83)$ & $1,806(19.58)$ & & $2,346(21.62)$ & & $491(23.82)$ & \\
\hline 3 & $307(6.10)$ & $524(5.68)$ & & $732(6.75)$ & & $156(7.57)$ & \\
\hline 4 & $410(8.15)$ & $737(7.99)$ & & $961(8.86)$ & & $245(11.89)$ & \\
\hline
\end{tabular}

Boldface type indicates statistical significance.

* Values represent the number of patients (\%) unless otherwise indicated. Percentages are based on the total number of patients per group regardless if data are missing from the category.

and morbidly obese: $35.05 \%$ [95\% CI $31.08 \%-39.02 \%$ ] with MD $=7.57 \%$ [95\% CI 4.66\%-10.48\%, p < 0.01]), VAS-BP scores (normal weight: 3.50 [95\% CI 2.85-4.15] and overweight: 3.51 [95\% CI 2.86-4.15] vs obese: 3.87 [95\% CI 3.25-4.50] with MD $=0.37$ [95\% CI 0.11-0.64, p $<0.01$ ] and morbidly obese: 4.43 [95\% CI 3.73-5.13] with $\mathrm{MD}=0.93$ [95\% CI 0.48-1.37, p < 0.01]), and VAS-LP scores (normal weight: 1.96 [95\% CI 1.50-2.43] and overweight: 2.03 [95\% CI 1.58-2.48] vs obese: 2.46 [95\% CI 2.03-2.89] with $\mathrm{MD}=0.50$ [95\% CI 0.23-0.77, $\mathrm{p}<0.01$ ] and morbidly obese: 2.96 [95\% CI 2.41-3.50] with MD $=0.99[95 \%$ CI $0.53-1.45, \mathrm{p}<0.01]$ ) were significantly worse for patients with a higher BMI.

Similar to the 12-month follow-up cohort, more patients in the higher BMI group rated their satisfaction as a 4 (9.93\% and $9.11 \%$ for normal weight and overweight, vs $11.10 \%$ and $10.48 \%$ for obese and morbidly obese, respectively; $\mathrm{p}<0.01)$, a $3(5.66 \%$ and $5.59 \%$ for normal weight and overweight vs $7.07 \%$ and $9.58 \%$ for obese and morbidly obese, respectively; $\mathrm{p}<0.01)$, or a $2(16.97 \%$ and $18.04 \%$ for normal weight to overweight vs $19.06 \%$ and $25.74 \%$ for obese and morbidly obese, respectively; $\mathrm{p}<0.01$ ) compared with those in the lower BMI group.

\section{ROC Analysis for BMI and Disability and Satisfaction at the 12- and 24-Month Follow-Ups}

According to the ROC analysis, we found that the cutoff value of BMI that predicted worsening disability at 12 months (compared with baseline) was $30.1 \mathrm{~kg} / \mathrm{m}^{2}$, with a sensitivity of $56 \%$ and specificity of $45 \%$ (AUC $=0.574$, 95\% CI 0.564-0.585) (vA). Furthermore, we found that a BMI of $30.1 \mathrm{~kg} / \mathrm{m}^{2}$ predicted surgery dissatisfaction at 12 months, with a sensitivity of $50 \%$ and a specificity of $44 \%$ (AUC $=0.532,95 \%$ CI 0.525-0.539) (Fig. 2B). At 24 months, we found that that the cutoff value of BMI that predicted worsening disability compared with baseline was $29.9 \mathrm{~kg} / \mathrm{m}^{2}$, with a sensitivity of $56 \%$ and a specificity of $45 \%$ (AUC $=0.575,95 \%$ CI $0.551-0.599$ ) (Fig. 2C). Also, we found that that the minimum BMI to predict surgery dissatisfaction at 24 months (compared with baseline) was measured as $29.9 \mathrm{~kg} / \mathrm{m}^{2}$, with a sensitivity of $51 \%$ and a specificity of $45 \%$ (AUC $=0.541,95 \%$ CI $0.523-0.558$ ) (Fig. 2D).

\section{Discussion}

\section{Principal Findings}

We found that patients who were obese or morbidly obese had significantly worse baseline ODI, VAS-BP, and VAS-LP scores than those who were normal weight or overweight in both the 12- and 24-month cohorts. We identified that the incidence of comorbidities increased with increasing BMI for both groups. At both the 12- and 24-month follow-ups after accounting for covariates, we found that while all patients had improvement in pain and disability scores, those with a lower BMI had significantly better outcomes and rated their satisfaction higher than those with a higher BMI. Furthermore, the ROC analysis revealed that the BMI cutoffs for predicting worsening disability and surgery dissatisfaction were $30.1 \mathrm{~kg} / \mathrm{m}^{2}$ and $29.9 \mathrm{~kg} / \mathrm{m}^{2}$ for the 12- and 24-month follow-ups, respectively. 
TABLE 4. Outcome differences between groups at 24 months

\begin{tabular}{|c|c|c|c|c|c|c|c|}
\hline Outcome Measure & $\begin{array}{l}\text { Normal Weight } \\
\quad(n=866)\end{array}$ & $\begin{array}{l}\text { Overweight } \\
(n=1,591)\end{array}$ & $\begin{array}{c}p \\
\text { Value }\end{array}$ & $\begin{array}{c}\text { Obese } \\
(n=1,810)\end{array}$ & $\begin{array}{c}p \\
\text { Value }\end{array}$ & $\begin{array}{l}\text { Morbidly Obese } \\
\qquad(n=334)\end{array}$ & $\begin{array}{c}\mathrm{p} \\
\text { Value }\end{array}$ \\
\hline \multicolumn{8}{|l|}{ ODI score $(95 \% \mathrm{Cl})$} \\
\hline Unadjusted mean & 19.42 (18.11 to 20.74) & 19.64 (18.66 to 20.63$)$ & & 23.95 (22.97 to 24.92$)$ & & 31.24 (28.84 to 33.64$)$ & \\
\hline Adjusted mean & 27.47 (23.87 to 31.08$)$ & 27.89 (24.36 to 31.41$)$ & & 30.46 (27.03 to 33.89$)$ & & 35.05 (31.08 to 39.02$)$ & \\
\hline Adjusted MD & & $0.41(-1.30$ to 2.12$)$ & 0.63 & 2.98 (1.24 to 4.72$)$ & $<0.01$ & 7.57 (4.66 to 10.48$)$ & $<0.01$ \\
\hline \multicolumn{8}{|l|}{ VAS-BP score $(95 \% \mathrm{CI})$} \\
\hline Unadjusted mean & 2.77 (2.57 to 2.96$)$ & 2.86 (2.72 to 3.00$)$ & & 3.38 (3.24 to 3.52$)$ & & 4.17 (3.83 to 4.52$)$ & \\
\hline Adjusted mean & 3.50 (2.85 to 4.15$)$ & 3.51 (2.86 to 4.15$)$ & & 3.87 (3.25 to 4.50$)$ & & 4.43 (3.73 to 5.13$)$ & \\
\hline Adjusted MD & & $0.00(-0.26$ to 0.25$)$ & 0.98 & 0.37 (0.11 to 0.64$)$ & $<0.01$ & 0.93 (0.48 to 1.37$)$ & $<0.01$ \\
\hline \multicolumn{8}{|l|}{ VAS-LP score $(95 \% \mathrm{Cl})$} \\
\hline Unadjusted mean & 2.23 (2.04 to 2.43 ) & 2.34 (2.20 to 2.49$)$ & & 2.79 (2.64 to 2.93 ) & & 3.46 (3.10 to 3.81$)$ & \\
\hline Adjusted mean & 1.96 (1.50 to 2.43$)$ & 2.03 (1.58 to 2.48$)$ & & 2.46 (2.03 to 2.89$)$ & & 2.96 (2.41 to 3.50$)$ & \\
\hline Adjusted MD & & $0.07(-0.20$ to 0.33$)$ & 0.63 & 0.50 (0.23 to 0.77$)$ & $<0.01$ & $0.99(0.53$ to 1.45$)$ & $<0.01$ \\
\hline \multicolumn{8}{|c|}{$\begin{array}{l}\text { Unadjusted mean NASS } \\
\text { score, } \mathrm{n}(\%)^{*}\end{array}$} \\
\hline 1 & $575(66.40)$ & $1,059(66.56)$ & \multirow{4}{*}{$<0.01$} & $1,121(61.93)$ & \multirow{4}{*}{$<0.01$} & $179(53.59)$ & \multirow{4}{*}{$<0.01$} \\
\hline 2 & $147(16.97)$ & $287(18.04)$ & & $345(19.06)$ & & $86(25.75)$ & \\
\hline 3 & $49(5.66)$ & $89(5.59)$ & & $128(7.07)$ & & $32(9.58)$ & \\
\hline 4 & $86(9.93)$ & $145(9.11)$ & & $201(11.10)$ & & $35(10.48)$ & \\
\hline
\end{tabular}

Boldface type indicates statistical significance.

* Values represent the number of patients (\%) unless otherwise indicated. Percentages are based on the total number of patients per group regardless if data are missing from the category.

\section{Higher BMI Is Correlated to Worse Patient-Reported Outcomes at the 12- and 24-Month Follow-Ups}

In our analysis, we found that patients in all BMI groups experienced improvements in disability and pain scores compared with baseline; however, higher BMI was correlated with higher disability and pain scores even after accounting for covariates such as comorbidities and previous spine surgery at the 12-month follow-up. In our ROC analysis, we found that $\mathrm{BMI} \geq 30.1 \mathrm{~kg} / \mathrm{m}^{2}$ resulted in worsening disability 12 months postoperatively. In a study looking into the relationship between obesity and outcomes postlaminectomy or microdecompression after 1 year for lumbar spinal stenosis, Giannadakis et al. found that less clinical improvement (in disability, back pain, and leg pain) was seen in the class II and III $\left(\geq 35 \mathrm{~kg} / \mathrm{m}^{2}\right)$ patients compared with nonobese patients and that obese patients were less likely to experience a minimal clinically important difference (MCID) after 1 year. ${ }^{27}$ Hence, BMI is an independent predictor of disability and pain at 12 months.

At the 24-month follow-up, adjusted disability and back pain scores similarly increased with increasing BMI and the differences became greater with higher BMIs. Similar to the ROC result for 12 months, we found that BMI $\geq$ $29.9 \mathrm{~kg} / \mathrm{m}^{2}$ resulted in worsening ODI scores in patients 24 months after spine surgery. This result agrees with that of Azimi et al., whose team found that a BMI $<29.1 \mathrm{~kg} /$ $\mathrm{m}^{2}$ was a predictive indicator for surgical success rate in patients with lumbar spinal canal stenosis at a 2-year follow-up. ${ }^{38}$ Moreover, a review by Knutsson et al. found that obese patients $\left(\mathrm{BMI}>30 \mathrm{~kg} / \mathrm{m}^{2}\right)$ had significantly worse disability and health-related quality-of-life scores, as well as lower mean improvement, than those of normal-weight patients $\left(\mathrm{BMI}<25 \mathrm{~kg} / \mathrm{m}^{2}\right) 2$ years after surgery. ${ }^{28}$ Furthermore, in a review of patients undergoing surgery for lumbar disc herniation from the Spine Patient Outcomes Research Trial (SPORT) data, Rihn et al. noted significantly less improvement in ODI score and all components of the SF-36 survey scores as well as the Sciatica Bothersomeness and Low-Back Pain Bothersomeness Indices in the obese $(\geq 30$ $\mathrm{kg} / \mathrm{m}^{2}$ ) population over 4 years postoperatively. ${ }^{29}$

\section{Higher BMI Patients Had Higher Expectations for Surgery Outcomes}

In terms of patient satisfaction, we found that patients with a higher BMI had higher expectations and were generally dissatisfied with the results of surgery compared with those with a normal BMI. In a study on obesity and lumbar decompressive laminectomies, Gepstein et al. also found that the number of "very dissatisfied patients" was higher among obese patients at an average follow-up of 64 months. ${ }^{30}$ Recent literature suggests that obesity contributes to low-back pain and greater rates of degenerative spine pathology, which contributes to a relatively high prevalence of obese patients undergoing elective lumbar surgery for relief. ${ }^{31}$ This high preoperative expectation can contribute to lower postoperative satisfaction..$^{32,33}$

\section{Implications}

For the 12-month follow-up group, we found that the greatest adjusted MDs in the patient-reported outcomes 

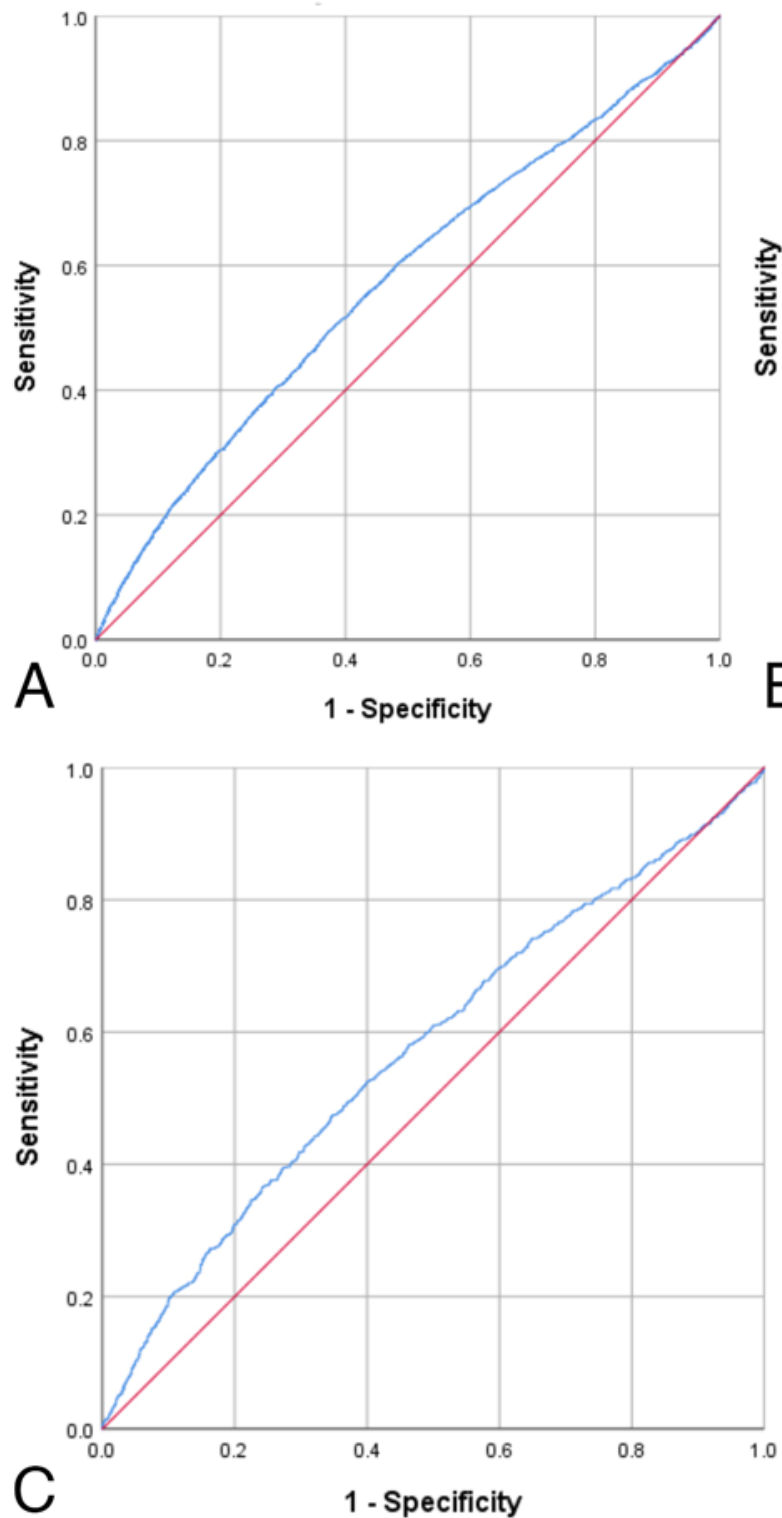
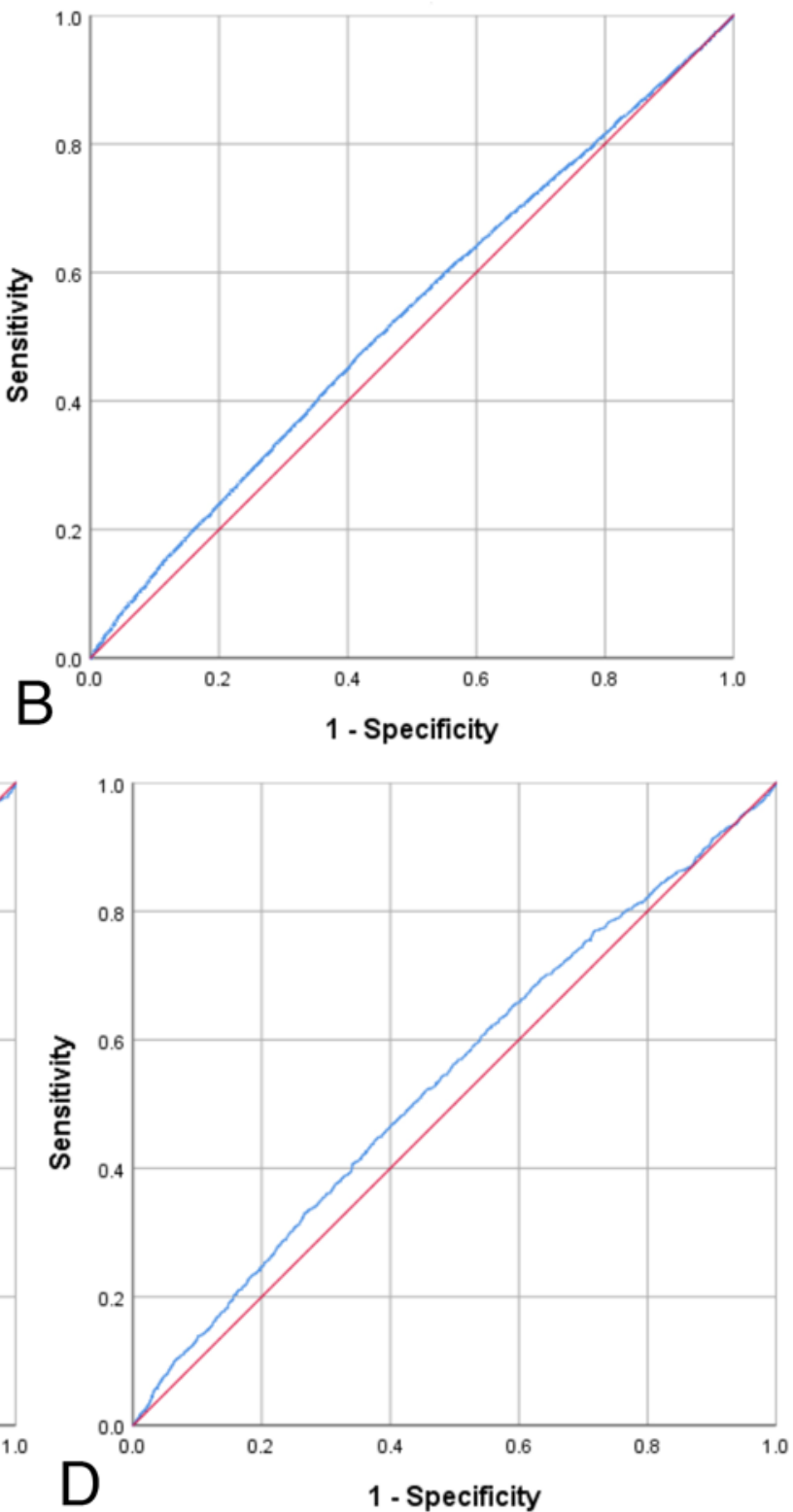

FIG. 2. A: ROC analysis for $B M I$ and disability at 12 months. $A U C=0.574 . A B M I \geq 30.12 \mathrm{~kg} / \mathrm{m}^{2}$ is associated with worsening disability at 12 months (ROC cutoff $>48$ ); $56 \%$ of the positive outcome ("worsening disability") would be correctly classified as positive, and $45 \%$ of the negative outcome ("no worsening disability") would be incorrectly classified as positive ("worsening disability"). B: ROC analysis for BMI and patient satisfaction at 12 months. AUC $=0.532$. A BMI $\geq 30.12 \mathrm{~kg} / \mathrm{m}^{2}$ is associated with "did not meet surgery satisfaction" at 12 months; $50 \%$ of the positive outcome ("did not meet surgery satisfaction") would be correctly classified as positive, and $44 \%$ of the negative outcome ("met surgery satisfaction") would be incorrectly classified as positive ("did not meet surgery satisfaction"). C: ROC analysis for BMl and disability at 24 months. AUC $=0.575$. A BMl $\geq 29.89 \mathrm{~kg} / \mathrm{m}^{2}$ is associated with worsening disability at 24 months (ROC cutoff $>48$ ); $56 \%$ of the positive outcome ("worsening disability") would be correctly classified as positive, and $45 \%$ of the negative outcome ("no worsening disability") would be incorrectly classified as positive ("worsening disability"). D: ROC analysis for BMl and patient satisfaction at 24 months. AUC $=0.541$. A BMI $\geq 29.89 \mathrm{~kg} / \mathrm{m}^{2}$ is associated with "did not meet surgery satisfaction" at 24 months; $51 \%$ of the positive outcome ("did not meet surgery satisfaction") would be correctly classified as positive, and $45 \%$ of the negative outcome ("met surgery satisfaction") would be incorrectly classified as positive ("did not meet surgery satisfaction"). Diagonal segments are produced by ties. Figure is available in color online only.

were found between normal-weight and morbidly obese patients: $5.91 \%$ for ODI, 0.67 points for the VAS-BP score, and 0.56 points for the VAS-LP score. Copay et al. reported that the MCID in patients who underwent lumbar spine surgery at their 1-year follow-up was $25.6 \%$ for ODI, 1.2 points for the VAS-BP score, and 1.6 points for the VASLP score. ${ }^{34}$ Asher et al. reported similar MCID results in patients who underwent surgery for degenerative lumbar 
spondylolisthesis at the 1-year follow-up, with $28.6 \%$ for ODI, 1.6 points for the VAS-BP score, and 1.7 points for the VAS-LP score. ${ }^{35}$ Hence, our results indicate that the pain and functional outcome differences between those of lower BMI and of higher BMI do not meet the MCID.

For the 24-month follow-up cohort, the greatest adjusted MDs of $7.57 \%$ for ODI, 0.93 points for VAS-BP score, and 0.99 points for VAS-LP score were found between the normal-weight and morbidly obese categories. In a study on patients who underwent a 2-year follow-up after decompression and fusion for lumbar stenosis, Parker et al. found that the MCID for this patient population was $14 \%$ for ODI, 4 points for VAS-BP, and 6 points for VAS-LP. ${ }^{36}$ Furthermore, in a patient sample who underwent any type of elective lumbar spinal surgery followed up at an average of 62 months, Patel et al. used three different methods of calculating the MCID to find the average of $23 \%$ for ODI and 27.5 points for VAS. ${ }^{37}$ We again see that the differences we saw in our study at 24 months do not meet the MCID reported in the literature.

However, this result does not necessarily mean that BMI should not be considered as a major factor of influence when considering surgical intervention in terms of patient-reported outcomes. The postoperative MCID scores are not universal across all spinal procedures and can vary depending on the criteria used for calculation, surgical treatment, pathology, and patient characteristics. ${ }^{37}$ Further large-scale research is needed to determine the difference in frequency of procedures depending on BMI and correlate the procedures with MCID to more precisely derive appropriate conclusions and recommendations for clinical practice.

\section{Study Limitations}

There are a few limitations to this study. First, we grouped patients who had a BMI $\leq 25 \mathrm{~kg} / \mathrm{m}^{2}$ as being at a normal weight, which means the group also included those who are underweight. Second, because this was a retrospective study using a national database, we could not control the standards used to determine the patients' disability and pain scores and the possible interobserver variability. Third, there could also be confounding factors that may have been present but were not accounted for that could have affected the statistical significance of the results. Furthermore, the difference seen between the two follow-up cohorts could be due to the difference in power from the sample size difference. Finally, the AUCs for both 12- and 24-month ROC analyses were below 0.7 , which implies that the predictions of clinical outcomes based on BMI are acceptable at best; however, this nevertheless indicates that BMI should be considered as one of the many factors in predicting the outcomes of lumbar surgery.

\section{Conclusions}

Patients experienced pain relief and improvement in disability after lumbar surgery across all BMIs, with lower BMI patients having greater improvement than higher BMI patients. BMIs $\geq 30.1 \mathrm{~kg} / \mathrm{m}^{2}$ and $\geq 29.9 \mathrm{~kg} / \mathrm{m}^{2}$ resulted in worsening disability and patient dissatisfaction at 12 and 24 months after lumbar surgery, respectively.

\section{References}

1. Finkelstein EA, Trogdon JG, Cohen JW, Dietz W. Annual medical spending attributable to obesity: payer-and servicespecific estimates. Health Aff (Millwood). 2009;28(5):w822w831.

2. Fruh SM. Obesity: Risk factors, complications, and strategies for sustainable long-term weight management. J Am Assoc Nurse Pract. 2017;29(S1):S3-S14.

3. Licht H, Murray M, Vassaur J, et al. The relationship of obesity to increasing health-care burden in the setting of orthopaedic polytrauma. J Bone Joint Surg Am. 2015;97(22):e73.

4. Segula D. Complications of obesity in adults: a short review of the literature. Malawi Med J. 2014;26(1):20-24.

5. Rihn JA, Radcliff K, Hilibrand AS, et al. Does obesity affect outcomes of treatment for lumbar stenosis and degenerative spondylolisthesis? Analysis of the Spine Patient Outcomes Research Trial (SPORT). Spine (Phila Pa 1976). 2012;37(23): 1933-1946.

6. Sabharwal S, Root MZ. Impact of obesity on orthopaedics. J Bone Joint Surg Am. 2012;94(11):1045-1052.

7. Becroft L, Ooi G, Forsyth A, et al. Validity of multi-frequency bioelectric impedance methods to measure body composition in obese patients: a systematic review. Int J Obes. 2019; 43(8):1497-1507.

8. Abdallah DY, Jadaan MM, McCabe JP. Body mass index and risk of surgical site infection following spine surgery: a metaanalysis. Eur Spine J. 2013;22(12):2800-2809.

9. Jiang J, Teng Y, Fan Z, et al. Does obesity affect the surgical outcome and complication rates of spinal surgery? A metaanalysis. Clin Orthop Relat Res. 2014;472(3):968-975.

10. Lingutla KK, Pollock R, Benomran E, et al. Outcome of lumbar spinal fusion surgery in obese patients: a systematic review and meta-analysis. Bone Joint J. 2015;97-B(10):13951404.

11. Kalanithi PA, Arrigo R, Boakye M. Morbid obesity increases cost and complication rates in spinal arthrodesis. Spine (Phila Pa 1976). 2012;37(11):982-988.

12. Djurasovic M, Bratcher KR, Glassman SD, et al. The effect of obesity on clinical outcomes after lumbar fusion. Spine (Phila Pa 1976). 2008;33(16):1789-1792.

13. Lucas F, Emery E, Dudoit T, Berger L. Influence of obesity on access-related complications during anterior lumbar spine interbody fusion. World Neurosurg. 2016;92:229-233.

14. Vaidya R, Carp J, Bartol S, et al. Lumbar spine fusion in obese and morbidly obese patients. Spine (Phila Pa 1976). 2009;34(5):495-500.

15. Chan AK, Bisson EF, Bydon M, et al. Obese patients benefit, but do not fare as well as nonobese patients, following lumbar spondylolisthesis surgery: an analysis of the Quality Outcomes Database. Neurosurgery. 2020;86(1):80-87.

16. Shamji MF, Cook C, Pietrobon R, et al. Impact of surgical approach on complications and resource utilization of cervical spine fusion: a nationwide perspective to the surgical treatment of diffuse cervical spondylosis. Spine J. 2009;9(1): 31-38.

17. McGirt MJ, Parker SL, Asher AL, et al. Role of prospective registries in defining the value and effectiveness of spine care. Spine (Phila Pa 1976). 2014;39(22)(suppl 1):S117-S128.

18. Asher AL, Speroff T, Dittus RS, et al. The National Neurosurgery Quality and Outcomes Database (N²QOD): a collaborative North American outcomes registry to advance valuebased spine care. Spine (Phila Pa 1976). 2014;39(22)(suppl 1): S106-S116.

19. Vandenbroucke JP, von Elm E, Altman DG, et al. Strengthening the Reporting of Observational Studies in Epidemiology (STROBE): explanation and elaboration. Epidemiology. 2007; 18(6):805-835.

20. Purnell JQ (ed). Definitions, Classification, and Epidemiology of Obesity. Endotext; 2018. 
21. Bijur PE, Silver W, Gallagher EJ. Reliability of the visual analog scale for measurement of acute pain. Acad Emerg Med. 2001;8(12):1153-1157.

22. Fairbank JC, Pynsent PB. The Oswestry Disability Index. Spine (Phila Pa 1976). 2000;25(22):2940-2952.

23. Daltroy LH, Cats-Baril WL, Katz JN, et al. The North American Spine Society Lumbar Spine Outcome Assessment Instrument: reliability and validity tests. Spine (Phila Pa 1976). 1996;21(6):741-749.

24. Werner DAT, Grotle M, Gulati S, et al. Criteria for failure and worsening after surgery for lumbar disc herniation: a multicenter observational study based on data from the Norwegian Registry for Spine Surgery. Eur Spine J. 2017;26(10): 2650-2659.

25. Kamarudin AN, Cox T, Kolamunnage-Dona R. Time-dependent ROC curve analysis in medical research: current methods and applications. BMC Med Res Methodol. 2017;17(1):53.

26. Jiang ZW, Li CJ, Wang L, Xia JL. Prevention and handling of missing data in clinical trials. Article in Chinese. Yao Xue Хие Bao. 2015;50(11):1402-1407.

27. Giannadakis C, Nerland US, Solheim O, et al. Does obesity affect outcomes after decompressive surgery for lumbar spinal stenosis? A multicenter, observational, registry-based study. World Neurosurg. 2015;84(5):1227-1234.

28. Knutsson B, Michaëlsson K, Sandén B. Obesity is associated with inferior results after surgery for lumbar spinal stenosis: a study of 2633 patients from the Swedish Spine Register. Spine (Phila Pa 1976). 2013;38(5):435-441.

29. Rihn JA, Kurd M, Hilibrand AS, et al. The influence of obesity on the outcome of treatment of lumbar disc herniation: analysis of the Spine Patient Outcomes Research Trial (SPORT). J Bone Joint Surg Am. 2013;95(1):1-8.

30. Gepstein R, Shabat S, Arinzon ZH, et al. Does obesity affect the results of lumbar decompressive spinal surgery in the elderly? Clin Orthop Relat Res. 2004;(426):138-144.

31. Marawar S, Girardi FP, Sama AA, et al. National trends in anterior cervical fusion procedures. Spine (Phila Pa 1976). 2010;35(15):1454-1459.

32. Soroceanu A, Burton DC, Diebo BG, et al. Impact of obesity on complications, infection, and patient-reported outcomes in adult spinal deformity surgery. J Neurosurg Spine. 2015; 23(5):656-664.

33. Mancuso CA, Reid MC, Duculan R, Girardi FP. Improvement in pain after lumbar spine surgery: the role of preoperative expectations of pain relief. Clin J Pain. 2017;33(2): 93-98.
34. Copay AG, Glassman SD, Subach BR, et al. Minimum clinically important difference in lumbar spine surgery patients: a choice of methods using the Oswestry Disability Index, Medical Outcomes Study questionnaire Short Form 36, and pain scales. Spine J. 2008;8(6):968-974.

35. Asher AL, Kerezoudis P, Mummaneni PV, et al. Defining the minimum clinically important difference for grade I degenerative lumbar spondylolisthesis: insights from the Quality Outcomes Database. Neurosurg Focus. 2018;44(1):E2 .

36. Parker SL, Mendenhall SK, Shau DN, et al. Minimum clinically important difference in pain, disability, and quality of life after neural decompression and fusion for same-level recurrent lumbar stenosis: understanding clinical versus statistical significance. J Neurosurg Spine. 2012;16(5):471-478.

37. Patel MS, Newey M, Sell P. A comparison of patient-reported outcome measures after spinal surgery. Bone Joint J. 2015; 97-B(3):366-371.

38. Azimi P, Yazdanian T, Shahzadi S, et al. Cut-off value for body mass index in predicting surgical success in patients with lumbar spinal canal stenosis. Asian Spine J. 2018;12(6): 1085-1091.

\section{Disclosures}

Dr. Shaffrey: consultant for Medtronic, NuVasive, and SI Bone; direct stock ownership in NuVasive; patent holder with Medtronic, $\mathrm{NuVasive}$, and Zimmer Biomet; and royalties from Medtronic and NuVasive.

\section{Author Contributions}

Conception and design: Park, Cook. Acquisition of data: Cook. Analysis and interpretation of data: Park, Garcia, Cook. Drafting the article: Park. Critically revising the article: Park. Reviewed submitted version of manuscript: Park, Garcia, Cook, Shaffrey. Approved the final version of the manuscript on behalf of all authors: Gottfried. Statistical analysis: Garcia. Study supervision: Gottfried.

\section{Correspondence}

Oren N. Gottfried: Duke University Medical Center, Durham, NC. oren.gottfried@duke.edu. 